\title{
Novel library synthesis of 3,4-disubstituted pyridin-2(1H)-ones via cleavage of pyridine-2-oxy-7-azabenzotriazole ethers under ionic hydrogenation conditions at room temperature
}

\author{
Romain Pierre ${ }^{1}$, Anne Brethon², Sylvain A. Jacques², Aurélie Blond², \\ Sandrine Chambon ${ }^{1}$, Sandrine Talano ${ }^{1}$, Catherine Raffin ${ }^{1}$, Branislav Musicki ${ }^{1}$, \\ Claire Bouix-Peter ${ }^{1}$, Loic Tomas ${ }^{1}$, Gilles Ouvry ${ }^{1}$, Rémy Morgentin², \\ Laurent F. Hennequin ${ }^{1}$ and Craig S. Harris ${ }^{* 1}$
}

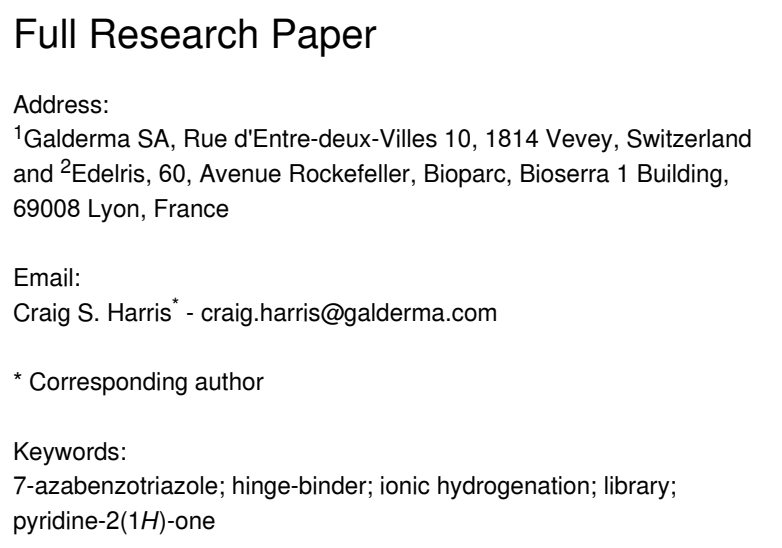

Beilstein J. Org. Chem. 2021, 17, 156-165. https://doi.org/10.3762/bjoc.17.16

Received: 21 October 2020

Accepted: 24 December 2020

Published: 18 January 2021

Associate Editor: D. Y.-K. Chen

(c) 2021 Pierre et al.; licensee Beilstein-Institut.

License and terms: see end of document.

\begin{abstract}
In our hands, efficient access to the 4-amino-3-carboxamide disubstituted pyridine-2(1H)-one kinase hinge-binder motif proved to be more challenging than anticipated requiring a significant investment in route scouting and optimization. This full paper focuses on the synthesis issues that we encountered during our route exploration and the original solutions we found that helped us to identify two optimized library-style processes to prepare our large kinase inhibitor library.
\end{abstract}

\section{Introduction}

During a recent medicinal chemistry program targeting a kinase to treat skin disorders, we identified the 4-amino-3-carboxamide disubstituted pyridine-2 $(1 H)$-one motif (1) as an interesting starting point. Recently, both Roche and Genentech researchers have described the first route to this scaffold for their FAK and EGFR mutant programs, respectively $[1,2]$. Both processes started from the versatile 4-iodo-2-methoxynicoti- naldehyde (3). Oxidation to the carboxylic acid followed by chlorodehydration afforded the key library building block acid chloride 2. The libraries were prepared in a 3-step manner: 1) amide coupling; 2) deprotection of the 2-methoxypyridine through hydrolysis at elevated temperatures; and 3) the final $\mathrm{S}_{\mathrm{N}} \mathrm{Ar}$ or Ullman step to introduce the amine vector with variable yields and chromatographic purification in between steps. 
As we planned to fix substitution at C-4 to a cis-diaminocyclohexane fragment and focus our main exploration from the amide vector at $\mathrm{C}-3$, we envisaged it would be more logical to exploit the cheaper and more readily-available precursor, 2-chloro-4-fluoronicotinic acid (4) with a goal of creating a rapid, 3-step route requiring a single preparative LC-MS purification at the end of the sequence (Figure 1).

\section{Results and Discussion}

\section{Exploration of the $\mathrm{C}-3$ amide vector:} formation of the pyridine-2-(1H)-one motif by palladium catalysis

We decided to validate the route by preparing morpholine amide 7 . The synthesis started by selective $S_{N} A r$ reaction with 4 and tert-butyl ((cis)-4-aminocyclohexyl)carbamate affording the intermediate nicotinic acid 5 in $70 \%$ yield without the need for chromatography. Subsequent amide coupling using TBTU afforded 2-chloro precursor 6 in excellent yield (Scheme 1).
We anticipated that the transformation of 2-chloropyridine precursor 6 to the final pyridine-2-( $1 H)$-one 7 would provide the biggest challenge, especially after introduction of the strong donor cyclohexylamine moiety at C-4 deactivating the pyridine ring towards nucleophilic attack (Table 1). No product was observed via direct $\mathrm{S}_{\mathrm{N}} \mathrm{Ar}$ using $\mathrm{KOH}$ (Table 1, entry 1) [3]. Acidic conditions (Table 1, entries 2-5) [4], where we can expect protonation thus activation of the pyridine ring towards nucleophilic attack, resulted in only traces of product along with hydrolysis of the amide moiety at C-3. Finally, we turned out attention to transition metal-catalyzed formation of phenols from aryl halides [5]. After another round of screening, we successfully applied palladium-catalyzed conditions discovered by the Buchwald group [6], using $\mathrm{KOH}$ as the nucleophile and $\mathrm{X}$-Phos as the ligand, to afford 7 in $83 \%$ isolated yield (Table 1, entry 6).

With these conditions in hand, we prepared a small library with different amides at C-3 to test the robustness of this new process before going into library production (Table 2). Howev-

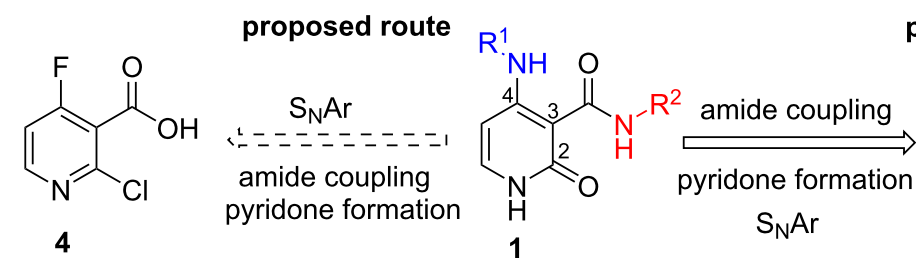

previous route

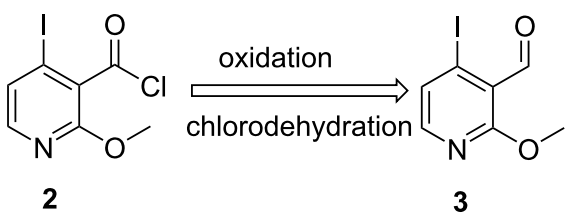

Figure 1: Retrosynthetic disconnection of our privileged kinase scaffold 1.

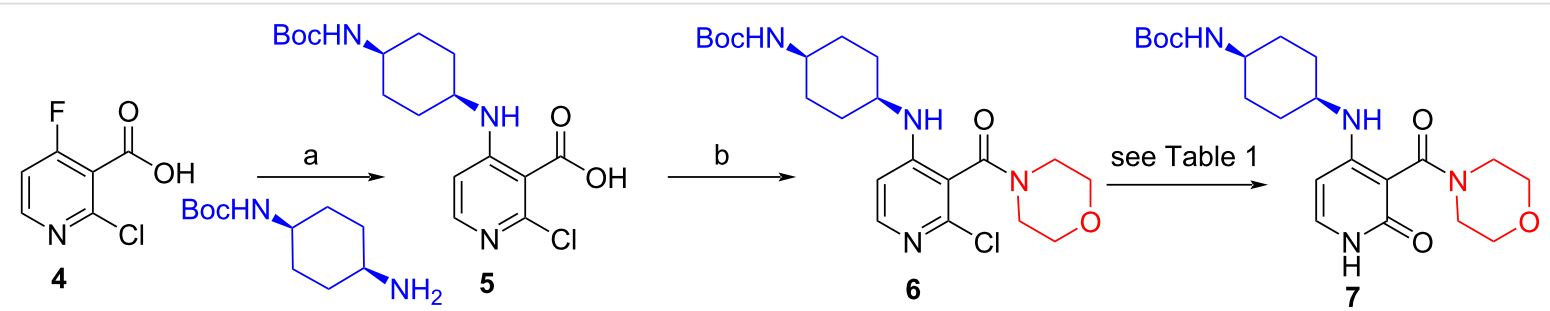

Scheme 1: Reagents and conditions: (a) MeOH, DIPEA, reflux, 70\%; b) TBTU, DIPEA, DMF, rt, $91 \%$.

Table 1: Selected results from conditions' screening for pyridin-2-(1H)-one formation $(7)$

\begin{tabular}{llll} 
Entry & Conditions & \% Conversion by UV-LC-MS & Isolated yield (\%) \\
\hline 1 & $\mathrm{KOH}\left(5\right.$ equiv), $\mathrm{DMSO}, 100{ }^{\circ} \mathrm{C}, 1 \mathrm{~h}$ & degradation & - \\
2 & $\mathrm{HCl} \mathrm{in} \mathrm{iPrOH}, \mathrm{H}_{2} \mathrm{O}, 50-100{ }^{\circ} \mathrm{C}$ & trace & - \\
3 & $\mathrm{C} . \mathrm{HCl}_{\mathrm{aq}}, 1,4-$ dioxane, $80-120{ }^{\circ} \mathrm{C}$ & trace & - \\
4 & $\mathrm{NH}_{4} \mathrm{OAc}, \mathrm{AcOH}, 120{ }^{\circ} \mathrm{C}, 3 \mathrm{~h}$ & trace & - \\
5 & $6 \mathrm{~N} \mathrm{HCl}_{\mathrm{aq}}, 130{ }^{\circ} \mathrm{C}, 2 \mathrm{~h}$ & trace & - \\
6 & $\mathrm{Pd}_{2}(\mathrm{dba})_{3}, \mathrm{X}-\mathrm{Phos}, \mathrm{KOH}$, dioxane, $100{ }^{\circ} \mathrm{C}, 4 \mathrm{~h}$ & 92 & 83
\end{tabular}


Table 2: Validation of library conditions. ${ }^{\text {a }}$

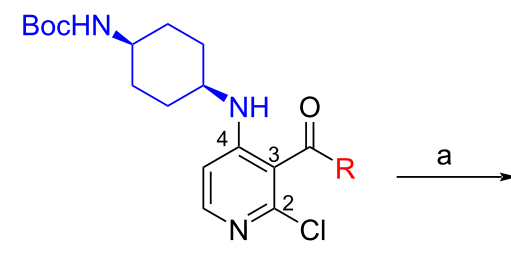

8a-e

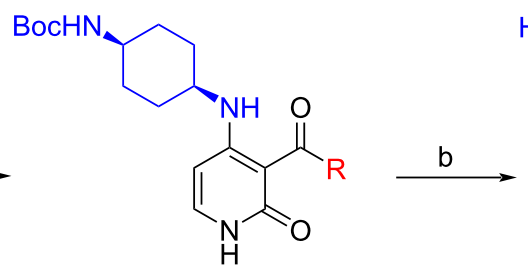

9a-e<smiles>[R]C(=O)c1c(N[C@H]2CC[C@H](N)CC2)cc[nH]c1=O</smiles>

$10 \mathrm{a}-\mathrm{e}$

\begin{tabular}{|c|c|c|c|}
\hline Compound & Amide $(\mathrm{R})$ & $\%$ Conversion of step a by UV-LC-MS & Isolated yield (\%) \\
\hline $10 a$ & & 95 & 80 \\
\hline $10 \mathrm{~b}$ & & 95 & 44 \\
\hline $10 c$ & & 100 & 66 \\
\hline $10 d^{b}$ & & 100 & $\begin{array}{l}37 \\
(0)^{c}\end{array}$ \\
\hline $10 e^{b}$ & & 100 & 19 \\
\hline
\end{tabular}

aReagents and condtions: (a) $\mathrm{Pd}_{2}(\mathrm{dba})_{3}$, X-Phos, $\mathrm{KOH}$, dioxane/water, $100{ }^{\circ} \mathrm{C}, 12 \mathrm{~h}$; b) $4 \mathrm{~N} \mathrm{HCl}$ in dioxane, $12 \mathrm{~h}$. ${ }^{\mathrm{b}} \mathrm{Cul}$ (0.2 equiv) was added; ${ }^{\mathrm{c}}$ same reaction in the absence of $\mathrm{Pd}_{2} \mathrm{dba}_{3}$ and $\mathrm{X}$-phos.

er, to our surprise, the process worked only for compounds with aliphatic amides at $\mathrm{C}-3$ affording only acceptable yields of pyridine intermediate $(\mathbf{9 a}-\mathbf{c})$ with the major byproduct arising from the dechlorination of $\mathbf{8}$. Application of the same conditions with aromatic amides at C-3 (8d,e) failed with only trace quantities of final product observed. We speculated that the aromatic carboxamide NH was fully deprotonated during the reaction and the amidic anion trapped the Pd catalyst irreversibly affording 12, thus halting the catalytic cycle (Scheme 2). We overcame this issue by adding 0.2 equiv of $\mathrm{Cu}(\mathrm{I})$, reported as a strong binder to the ortho-amino aromatic carboxamides [7], which served as a sacrificial metal cation, preventing $\mathrm{Pd}$ ligation and permitting the reaction to turnover resulting in albeit poor isolated yields of 9d,e (Table 2). All attempts to carry out the reaction using only $\mathrm{CuI}$ failed, confirming that Pd was necessary to catalyze this transformation. It was preferential to purify the Boc protected intermediates $9 \mathbf{a}-\mathbf{e}$ by Prep-LC-MS as the final products $10 \mathbf{a}-\mathbf{e}$ were difficult to purify owing to their particularly poor solubility in the mobile phase. The final products were delivered as their $\mathrm{HCl}$ salts following Boc deprotection using $\mathrm{HCl}$ in dioxane overnight.

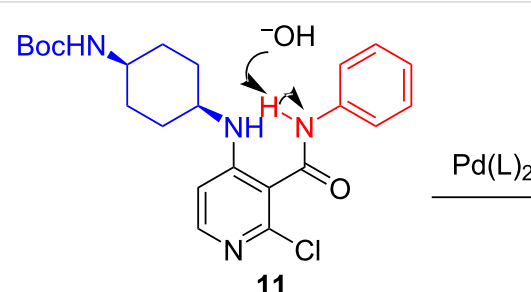

11<smiles>O=C(NC1CCC(Nc2ccnc(Cl)c2C(=O)N(c2ccccc2)c2ccccc2)CC1)c1ccccc1</smiles>

12

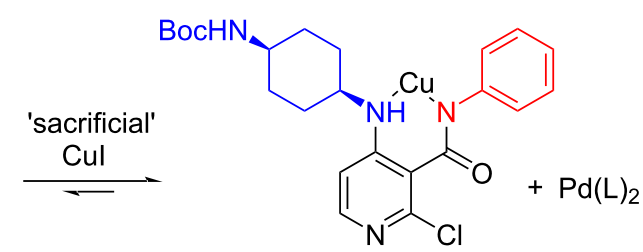

13

Scheme 2: Proposed mechanistic explanation for the liberation of the Pd catalytic cycle after addition of sacrificial $\mathrm{Cu}(\mathrm{I})$. 


\section{Exploration of the C-3 amide vector: formation of the pyridine-2 $(1 H)$-one motif by ionic hydrogenative cleavage of $\mathrm{C}-2-\mathrm{OAt}$ ether}

Encouraged by our results, we started the library production planning to use the 3 -step process requiring 2 purification steps by preparative LC-MS. However, as we planned to introduce a significant amount of steric and electronic diversity from the C-3 amide vector, we switched the amide coupling agent from TBTU to the more reactive HATU $[8,9]$. To our surprise, the amide coupling step furnished almost quantitatively the C2-OAt ether 15 [10] and only traces of the expected $\mathrm{C} 2-\mathrm{Cl}$ amide product 14 . Closer inspection of the reaction progression by UV-LC-MS revealed the expected product $\mathbf{1 4}$ is formed first and is slowly transformed to $\mathbf{1 5}$ overnight. We postulated that the acidic HOAt $\left(\mathrm{p} K_{\mathrm{a}}=3.76\right)$ liberated from the coupling reaction must be protonating thus activating the basic pyridine ring toward $\mathrm{S}_{\mathrm{N}}$ Ar with the ${ }^{-} \mathrm{OAt}$ anion in an intermolecular or intramolecular fashion (Scheme 3). We saw this observation as having the potential to solve our hydrolysis issues and decided to explore it further.

Inspection of the literature revealed that activated ethers (e.g., OBt) have been utilized in synthetic strategies as masked leaving groups notably on azines and displaced using an excess of nucleophile under high temperatures. More relevantly, among the few references, hydrolysis of the (het)aryl-OBt bond was most documented in a refluxing mixture of $\mathrm{AcOH} / \mathrm{H}_{2} \mathrm{O}$ [11]. We anticipated that under these acidic conditions, hydrolysis of our py-OAt ether $\mathbf{1 5}$ would be accompanied by in situ deprotection of the Boc group to afford directly our final pyridin-2-( $1 H)$-one products $\mathbf{1 6}$ and thereby eliminating a purification stage compared to the previous route. As literature was scarce for this transformation and we were also concerned about hydrolysis of the amide bond under aqueous acidic conditions, we decided to carry out a final reaction conditions' screening using $\mathbf{1 5}$ before starting the library production (Table 3).

As attested by the results presented in Table 3, the Py-OAt ether was much easier to hydrolyze than the $\mathrm{Py}-\mathrm{Cl}$ bond (Table 1). Using conditions described in the literature (Table 3, entry 1), we obtained a $45 \%$ isolated yield of $\mathbf{1 6}$ with side products arising namely from acetylation of the product that were easily removed by preparative LC-MS. Using aqueous $\mathrm{HCl}$ led to severe degradation with the dominant impurity coming from cleavage of the amide bond (Table 3, entry 2) and dissolving metal reduction conditions using zinc were quickly excluded as just $30 \%$ conversion was achieved with the added work-up complications (Table 3, entry 3). Finally and rather fortuitously, we turned our attention to ionic hydrogenation conditions [12]. Although ionic hydrogenation conditions have never been cited for this type of transformation, we anticipated that, if successful, sample preparation would be further simplified for the final preparative LC-MS purification step owing to the high volatility of the reaction medium compared to $\mathrm{AcOH} / \mathrm{H}_{2} \mathrm{O}$ mixtures (Table 3, entry 1). To our delight, our first attempt using $\mathrm{CH}_{2} \mathrm{Cl}_{2}$ as the solvent at $\mathrm{rt}$ afforded a very slow but clean conversion to $\mathbf{1 6}$ after $10 \mathrm{~d}$ at $\mathrm{rt}$ (Table 3, entry 4). The reaction time was reduced to $24 \mathrm{~h}$ by heating the reaction at $50{ }^{\circ} \mathrm{C}$ (Table 3, entry 5).

To decrease reaction times further, we carried out the reaction in neat TFA/TES mixture (4:1 v/v, 5 volumes) and obtained a $62 \%$ conversion at just $\mathrm{rt}$ after $24 \mathrm{~h}$ (Table 3, entry 6). The product distribution was even further improved by addition of water to the reaction mixture to avoid a trifluoroacetamide impurity, presumably forming by reaction with the cyclohexylamine moiety. In the absence of triethylsilane (TES), only deprotection of the Boc group was observed when using TFA (Table 3, entry 8) and when the reaction was carried out in mixture of TFA $/ \mathrm{H}_{2} \mathrm{O}$ (4:1) over 4 days, only $12 \%$ of desired pyridine-2-(1H)-one 22 was observed (Scheme 4).

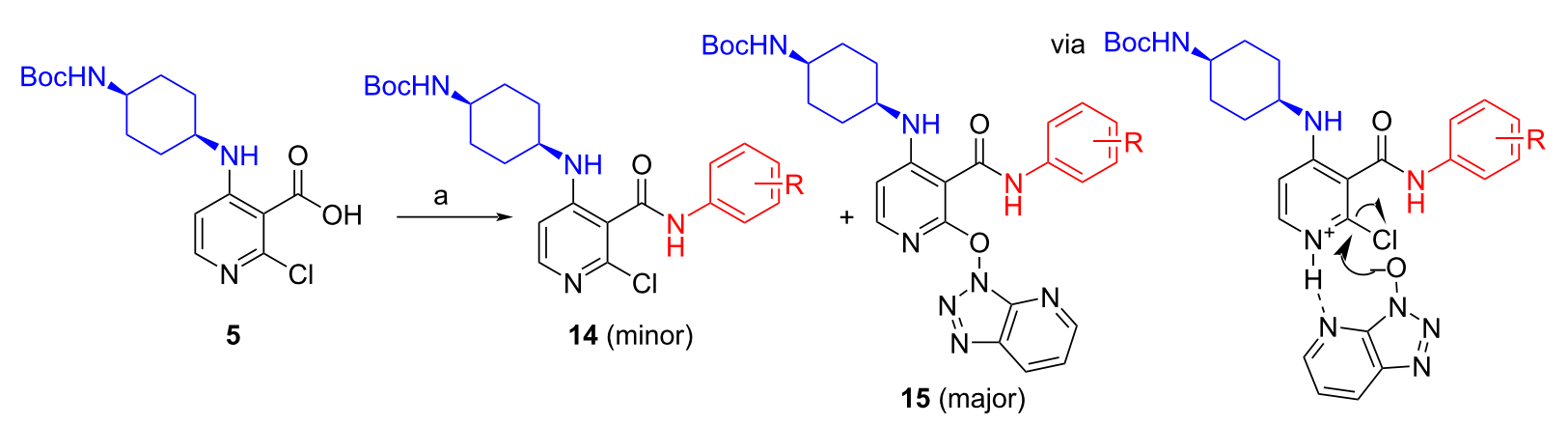

Scheme 3: Formation of C2-OAt ether 15 using HATU. Reagents and condtions: (a) HATU, DIPEA, DCM, rt, 16 h, ((14) 5\%, (15) 95\% conversion by UV-LC-MS), $58 \%$ isolated yield (15). 
Table 3: Selected results from conditions screening to form pyridin-2-(1H)-one 16
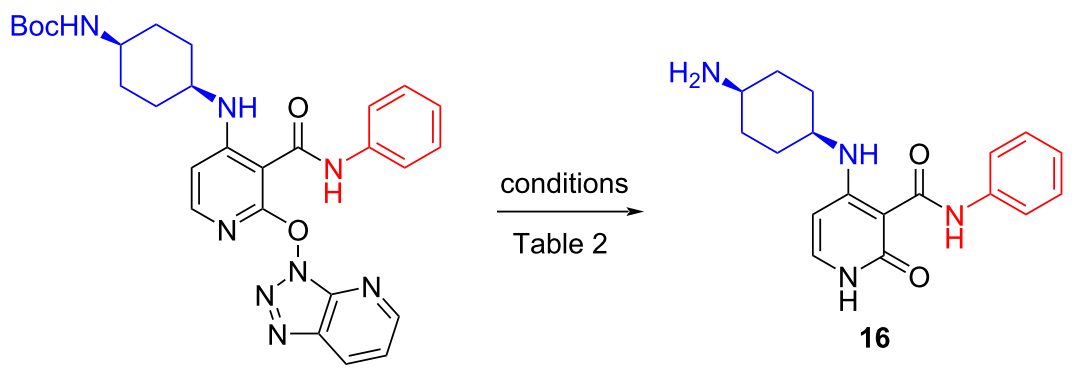

15

\begin{tabular}{|c|c|c|c|}
\hline Entry & Conditions & $\begin{array}{l}\text { \% Conversion by } \\
\text { UV-LC-MS }\end{array}$ & Isolated yield (\%) \\
\hline 1 & $\mathrm{AcOH} / \mathrm{H}_{2} \mathrm{O}(4: 1), 140^{\circ} \mathrm{C}, 1 \mathrm{~h}$ & 65 & 45 \\
\hline 2 & $2 \mathrm{~N} \mathrm{HCl}_{\mathrm{aq}}, \mathrm{MeOH}, 100^{\circ} \mathrm{C}$ & 15 & - \\
\hline 3 & $\mathrm{Zn}_{\text {solid }}, \mathrm{AcOH} / \mathrm{H}_{2} \mathrm{O}, 70^{\circ} \mathrm{C}, 5 \mathrm{~h}$ & 30 & - \\
\hline 4 & TFA, TES, DCM, rt, $10 \mathrm{~d}$ & 76 & - \\
\hline 5 & TFA, TES, $1,2-\mathrm{DCE}, 50^{\circ} \mathrm{C}, 24 \mathrm{~h}$ & 57 & $\mathrm{~N} / \mathrm{I}$ \\
\hline 6 & TFA/TES (4:1), rt, $24 \mathrm{~h}$ & 62 & 45 \\
\hline 7 & TFA/TES/ $\mathrm{H}_{2} \mathrm{O}(4: 1: 1), \mathrm{rt}, 24 \mathrm{~h}$ & 69 & 61 \\
\hline $8^{a}$ & neat TFA & - & - \\
\hline 9 & $\mathrm{TFA} / \mathrm{H}_{2} \mathrm{O}(4: 1), 96 \mathrm{~h}$ & 12 & $\mathrm{~N} / \mathrm{I}$ \\
\hline
\end{tabular}

aMajor product corresponded to loss of Boc group but retention of C2-OAt ether; $\mathrm{N} / \mathrm{I}=$ not isolated; TES = triethylsilane:

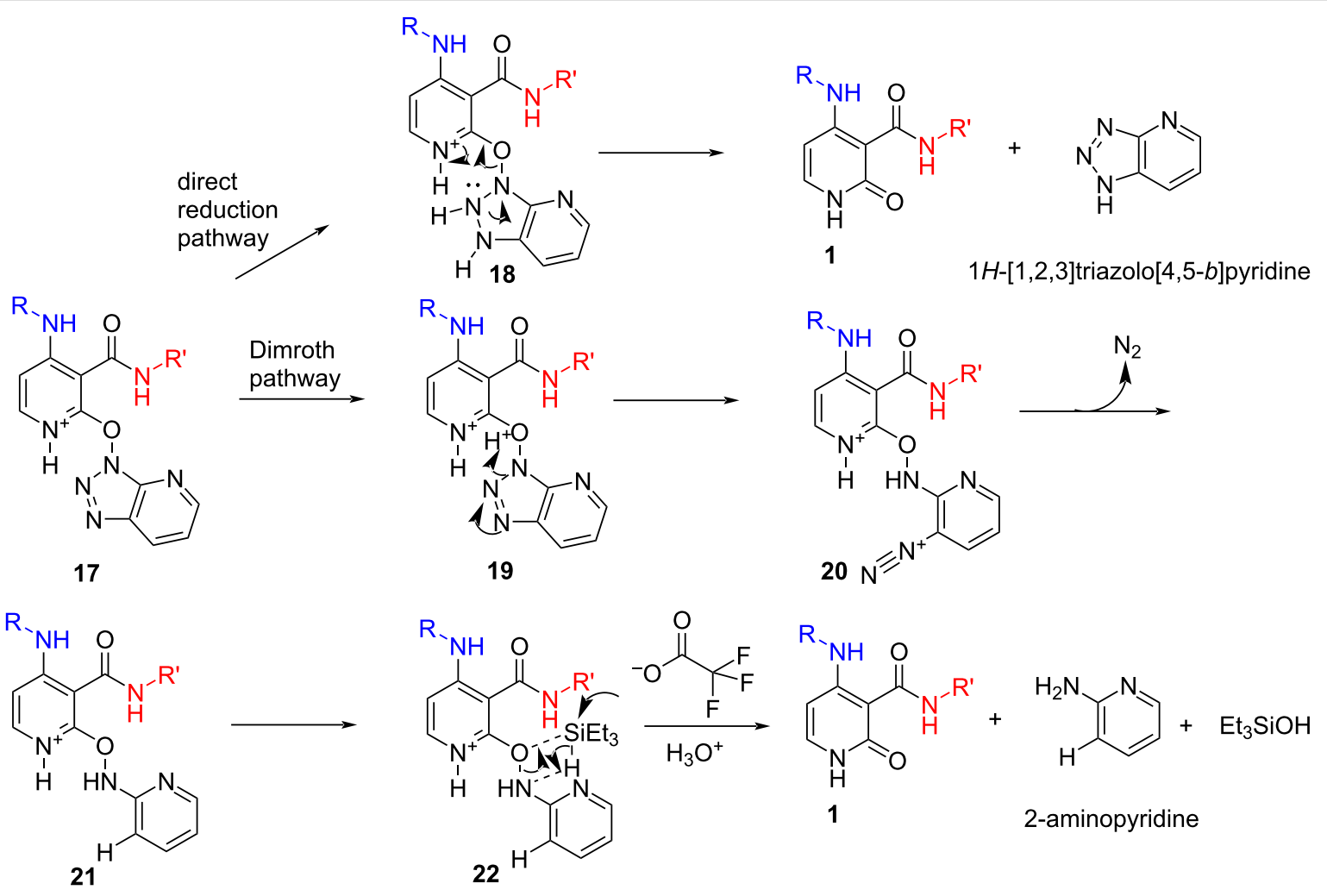

Scheme 4: Proposed mechanistic pathways for the transformation of Py-OAt ethers 17 to the pyridin- $2 \mathrm{H}$-one 1 motif. 
Despite literature analogies being scarce in this area [13,14], we propose that the reaction could occur through 2 possible pathways. The first proposition concerns the direct reduction of the $\mathrm{N}(3)=\mathrm{N}(2)$ double bond of the 7-azabenzotriazole ring to the 7-azabenzotriazoline ring 18 and cleavage of the $\mathrm{N}-\mathrm{O}$ bond through delocalization of the lone pair at N-2 to liberate $\mathbf{1}$ and $1 H$-[1,2,3]triazolo[4,5-b]pyridine as the byproduct. The second pathway occurs through 4 key steps: a) activation of the pyridine in the acidic media; b) ring-opening of the triazole moiety through a Dimroth rearrangement process affording 20 (reaction becomes instantly bright red); c) reduction of diazonium species to afford intermediate 21, observed by UV-LC-MS; and finally d) reductive cleavage of the -O-NH- bond, usually carried out under catalytic hydrogenation [15], through addition of the hydride from triethylsilane to afford $\mathbf{1}$ after in situ hydrolysis of the triethylsilyloxy bond. HOAt alone does not degrade under these conditions and intermediate $\mathbf{2 1}$ has been identified and characterized from the reaction medium although we did not identify 2 -aminopyridine or any logical end product arising from the OAt ether degradation (Scheme 4) [16].

With these novel conditions in hand, we started the library production based on a 3-step, one-pot process: 1) amide coupling using HATU followed by removal of the solvent by sparging with nitrogen; 2) Boc deprotection with concomitant ionic reduction of the pyridine-OAt bond of the intermediate 23 was achieved by dissolving the residue in the TFA/TES/ $\mathrm{H}_{2} \mathrm{O}(3: 1: 1$ $\mathrm{v} / \mathrm{v} / \mathrm{v}$ ) mixture; 3 ) removal of the volatiles by sparging followed by purification of the residue by mass-triggered preparative LC-MS to afford the final compounds 24 . In practice, the process was very efficient affording 60 final compounds with a median yield of $47 \%$. Best results were obtained with electronrich anilines (e.g., compounds 24a-d) and aliphatic amines (e.g., compounds 24k-l). For electron-deficient anilines (e.g., compounds $24 \mathrm{e}-\mathrm{g}$ ), the reaction mixtures were heated to $65^{\circ} \mathrm{C}$ to complete the amide coupling reaction. For the least reactive anilines (e.g., compounds $\mathbf{2 4 h}, \mathbf{i}$ ), HATU only afforded trace quantities of the amide even at $65{ }^{\circ} \mathrm{C}$. However, satisfactory results were obtained by generating the acid chloride in situ by adding a 3 fold excess of $\mathrm{POCl}_{3}$ and heating the reaction mixtures to $60{ }^{\circ} \mathrm{C}$ over $4 \mathrm{~h}$ [17]. In turn, the $\mathrm{C}-2-\mathrm{Cl}$ intermediates were transformed to their $\mathrm{C}-2-\mathrm{OBt}$ ethers using an excess of $\mathrm{HOBt} \cdot \mathrm{H}_{2} \mathrm{O}$ in refluxing DCM to facilitate the final hydrolysis step to the desired pyridine-2-( $1 H)$-one products $24 \mathbf{h}, \mathbf{i}$. The low yield obtained for the 3-(2-(dimethylamino)ethyl)aniline analogue $24 \mathbf{j}$ was due to the fact the 2-Cl-Py did not transform to the OAt ether in situ and the subsequent hydrolysis step was very sluggish. We postulate that the presence of the more basic $N, N$,-dimethylaminoethyl side chain $\left(\mathrm{p} K_{\mathrm{a}} \approx 11\right)$ must prevent protonation and activation of the pyridine towards $\mathrm{S}_{\mathrm{N}} \mathrm{Ar}$ with HOAt (Table 4).

Table 4: Selected compounds prepared using the optimized library process. ${ }^{\text {a }}$

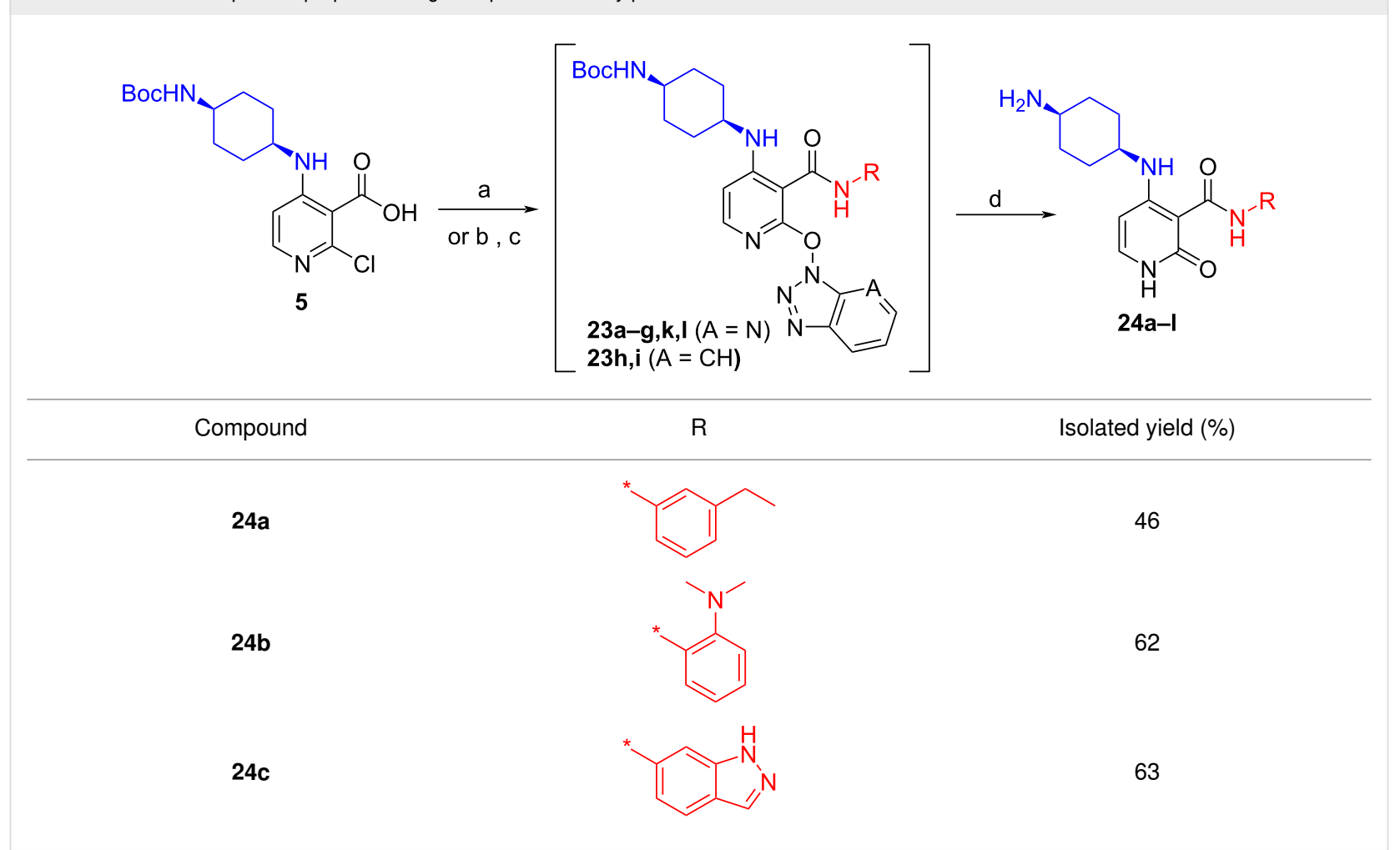


Table 4: Selected compounds prepared using the optimized library process. ${ }^{\text {a }}$ (continued)

24d

$24 e^{b}$

$24 f^{b}$

$\mathbf{2 4} \mathrm{g}^{\mathrm{b}}$

$24 h^{\mathrm{C}}$

$24 i^{C}$

$24 j^{d}$

24k

24I<smiles>Cc1ccncc1</smiles>

72

48<smiles>CCS(=O)(=O)c1cccc(C)c1</smiles><smiles>Cc1ccc(C(F)(F)F)cc1</smiles>

77

aOptimized process to delivery pyridin-2-(1H)-one library 24a-I. Reagents and conditions: (a) HATU, DIPEA, DCM, rt, assumed quant.; b) POCl 3 , $\mathrm{MeCN}, \mathrm{rt}, 6{ }^{\circ} \mathrm{C}, 4 \mathrm{~h}$; c) $\mathrm{HOBt} \cdot \mathrm{H}_{2} \mathrm{O}$, DCM, reflux, assumed quant.; (d) TFA $/ \mathrm{TES} / \mathrm{H}_{2} \mathrm{O}(3: 1: 1,5 \mathrm{v} / \mathrm{v} / \mathrm{v}), \mathrm{rt}, 24 \mathrm{~h}, 39-82 \%$ or $\mathrm{AcOH} / \mathrm{H}_{2} \mathrm{O}(4: 1), 140{ }^{\circ} \mathrm{C}$, microwave irradiation, $2 \mathrm{~h}, 7-55 \%$. bHATU reaction mixtures were heated to $65^{\circ} \mathrm{C}$ to complete the amide-coupling reaction; ${ }^{\mathrm{C}} \mathrm{compounds}$ prepared using $\mathrm{POCl}_{3}$ method and $\mathrm{AcOH} / \mathrm{H}_{2} \mathrm{O}(4: 1)$ at $140{ }^{\circ} \mathrm{C}$ was used for step d; donly the $\mathrm{C}-2-\mathrm{Cl}$ intermediate was formed and $\mathrm{AcOH} / \mathrm{H}_{2} \mathrm{O}(4: 1)$ at $140{ }^{\circ} \mathrm{C}$ was used for step d.

\section{Exploration of the C-4 amine vector}

As we moved forwards in the program, we were eager to develop our understanding of SARs (structure-activity relationships) from the $\mathrm{C}-4$ vector. Although we could have adopted the same methodology as described in Scheme 5 for this exploration, we decided to focus on developing a more convergent library process than Genentech's 3-step sequence from 2 (Scheme 1), aiming at introducing the amine moiety at C-4 at the end of the process. We envisaged a rapid, 2-step one-pot library process (amide coupling, sparging to dryness followed by C-4-I displacement) with the key pyridine-2-(1H)-one hinge-binding motif revealed from the beginning of the process.

Our exploration started from commercially available 2-fluoro-4iodonicotinic acid (25). Amide coupling using HATU led solely to 26 with no traces of the C-2-OAt ether presumably due to the lower basicity of $\mathbf{2 6}$ compared to $\mathbf{8}$, therefore, activation via protonation of the pyridine was not occurring. With a view to capitalize on our knowledge acquired so far on this scaffold, we decided to force the transformation to the OBt ether by $\mathrm{S}_{\mathrm{N}} \mathrm{Ar}$ under basic conditions. To our surprise, the iodide at $\mathrm{C}-4$ was selectively displaced to afford only $\mathbf{2 7}$. We propose that this observation can be explained by HSAB (hard-soft-acid-base) theory whereby the soft ${ }^{-} \mathrm{OBt}$ anion preferentially reacts at the soft C-4-I center [18]. As expected, reacting 26 first with tertbutyl ((cis)-3-aminocyclobutyl)carbamate afforded the undesired regioisomer $\mathbf{2 8}$ as the majority product (Scheme 5).

As we were unable to exploit intermediate 26, we turned our attention to the pyridine-2-(1H)-one building block 30, easily prepared by hydrolysis of the C-2-F bond in high yield and without the need for chromatography [19]. Amide coupling was 


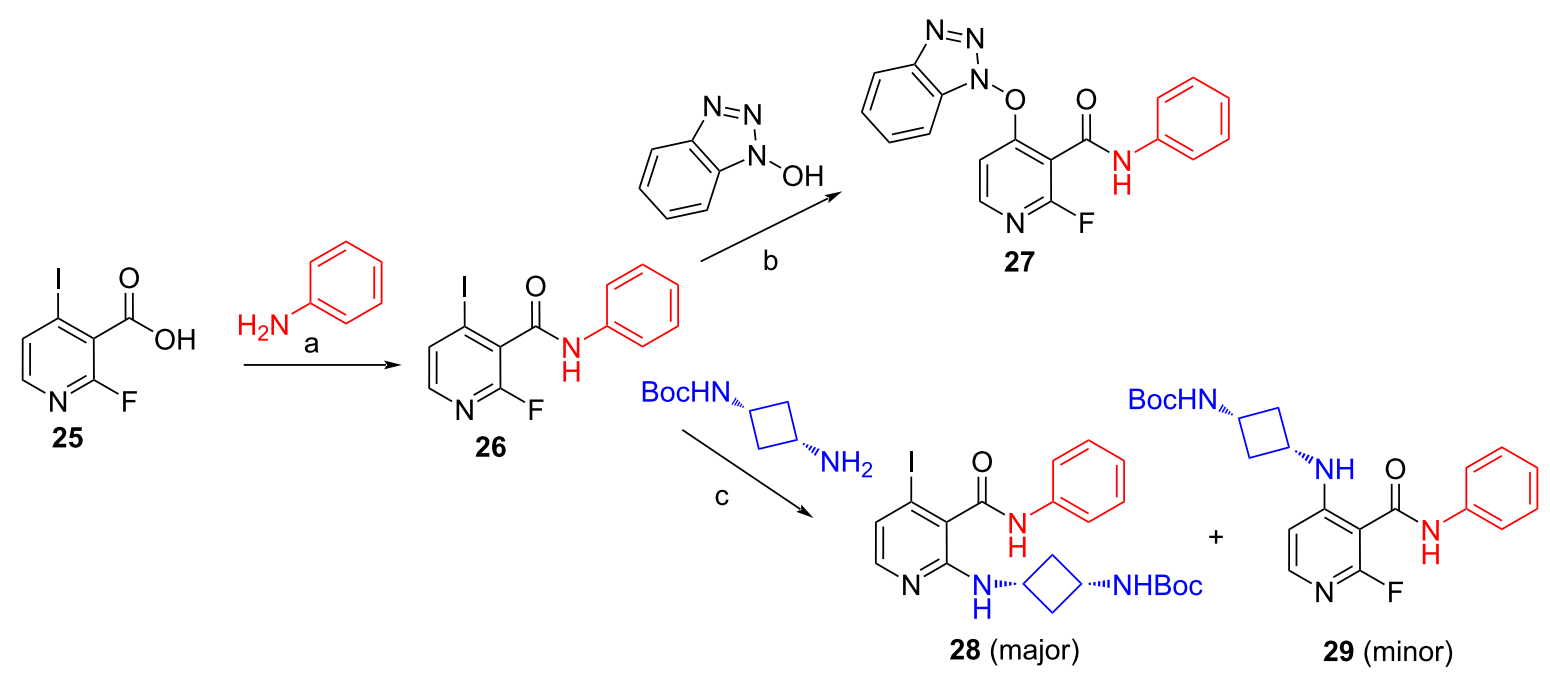

Scheme 5: Failure to exploit logical convergent building block 26. Reagents and conditions: a) HATU, DIPEA, DCM, rt, 16 h, $96 \%$; b) HOBt· $\mathrm{H}_{2} \mathrm{O}$, $\mathrm{K}_{2} \mathrm{CO}_{3}, \mathrm{DMF}, 80^{\circ} \mathrm{C}, 87 \%$; c) DIPEA, DMF, $80{ }^{\circ} \mathrm{C}, 28(80 \%), 29(20 \%)$.

best carried out under acidic coupling conditions by pre-activating 30 using EDCI, pentylfluorophenol (Pfp-OH) in the presence of one equivalent pyridine and adding aniline dropwise over a few minutes. Under basic coupling conditions (e.g., HATU, DIPEA), complex mixtures were obtained with less than $5 \%$ conversion to the desired amide product 31 . The library process was completed by carrying out the nucleophilic aromatic substitution with a 3 -fold excess of amine in DMF at $60{ }^{\circ} \mathrm{C}$ overnight to afford 32a-h, after a removal of Boc or Cbz groups [20] where present (Scheme 6).

\section{Conclusion}

In conclusion, we have developed novel, complementary multiparallel synthetic routes permitting the exploitation of the C-3 then $\mathrm{C}-4$ vectors or vice versa to deliver our library of novel 3,4-disubstituted pyridin-2(1H)-one kinase inhibitors starting from readily-available 2-chloro-4-fluoronicotinic acid and 2-fluoro-4-iodonicotinic acid, respectively. Perhaps the highlight of our library route development was the novel transformation to the desired pyridin-2(1H)-one motif via in situ forma-
Table 5: Selected compounds prepared using the optimized library process to explore the $\mathrm{C}-4$ vector.

Compound $\quad \mathrm{R}^{1} \quad \mathrm{R}^{2} \quad \begin{aligned} & \text { Isolated yield } \\ & \text { C }\end{aligned}$

$32 a$

$\mathrm{H}_{2} \mathrm{~N} \widehat{\mathrm{H}}^{*} 44$

$32 b$ $\mathrm{H}_{2} \mathrm{~N}_{\text {I!n. }}$

32c

32d

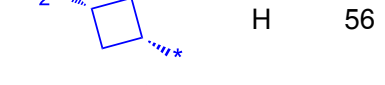<smiles>CCC1CCNCC1</smiles><smiles>CCC1CCOCC1</smiles>

$32 e$

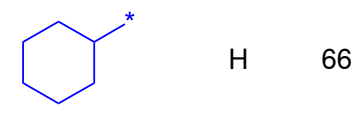

$32 f$

71

7<smiles>C1CCOCC1</smiles> 
Table 5: Selected compounds prepared using the optimized library process to explore the $\mathrm{C}-4$ vector. (continued)
$32 \mathrm{~g}$

$32 \mathrm{~h}$<smiles>CCCCN(C)C</smiles>

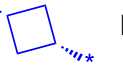
$n-\mathrm{PrO}_{2} \mathrm{SHN}$

tion of the C2-OAt ether during HATU coupling and its cleavage under ionic hydrogenation conditions at just room temperature.

\section{Supporting Information}

\section{Supporting Information File 1}

Detailed experimental protocols and supporting ${ }^{1} \mathrm{H}$,

${ }^{13} \mathrm{C}$ NMR, LC-MS characterization data and spectra for all compounds.

[https://www.beilstein-journals.org/bjoc/content/ supplementary/1860-5397-17-16-S1.pdf]

\section{Acknowledgements}

The authors would like to thank Professor Fabien Gagosz (Ottawa, CA) for interesting exchanges surrounding the mechanism and Mr Grégoire Mouis and Mlle Ghizlane El-Bazbouz for their help in purifying this large library.

\section{ORCID ${ }^{\circledR}$ iDs}

Romain Pierre - https://orcid.org/0000-0002-2278-7540 Loic Tomas - https://orcid.org/0000-0003-3990-3752 Rémy Morgentin - https://orcid.org/0000-0003-3144-4360 Craig S. Harris - https://orcid.org/0000-0002-1136-8236

\section{References}

1. Georges, G.; Kaluza, K.; Koerner, M.; Reiff, U.; Scheiblich, S.; Von der Saal, W.; Weigand, S. Pyridoneamide derivatives as focal adhesion kinase (fak) inhibitors and their use for the treatment of cancer. WO Pat. Appl. WO2009024332A1, Feb 26, 2009.

2. Bryan, M. C.; Burdick, D. J.; Chan, B. K.; Chen, Y.; Clausen, S.; Dotson, J.; Eigenbrot, C.; Elliott, R.; Hanan, E. J.; Heald, R.; Jackson, P.; La, H.; Lainchbury, M.; Malek, S.; Mann, S. E.; Purkey, H. E.; Schaefer, G.; Schmidt, S.; Seward, E.; Sideris, S.; Wang, S.; Yen, I.; Yu, C.; Heffron, T. P. ACS Med. Chem. Lett. 2016, 7, 100-104. doi:10.1021/acsmedchemlett.5b00428

3. Feng, J.; Haynes, N.-E.; Hermann, J. C.; Kim, K.; Liu, J.-J.; Scott, N. R.; Yi, L.; Zak, M.; Zhao, G. Pyrazolopyrimidone and pyrazolopyridone inhibitors of tankyrase. WO Pat. Appl. WO2013182546A1, Dec 12, 2013.
4. Siu, T.; Kozina, E. S.; Jung, J.; Rosenstein, C.; Mathur, A.; Altman, M. D.; Chan, G.; Xu, L.; Bachman, E.; Mo, J.-R.; Bouthillette, M.; Rush, T.; Dinsmore, C. J.; Marshall, C. G.; Young, J. R. Bioorg. Med. Chem. Lett. 2010, 20, 7421-7425. doi:10.1016/j.bmcl.2010.10.031

5. Liu, Y.; Liu, S.; Xiao, Y. Beilstein J. Org. Chem. 2017, 13, 589-611. doi:10.3762/bjoc.13.58 See for a recent review.

6. Anderson, K. W.; Ikawa, T.; Tundel, R. E.; Buchwald, S. L. J. Am. Chem. Soc. 2006, 128, 10694-10695. doi:10.1021/ja0639719

7. Vasková, Z.; Stachová, P.; Krupkováa, L.; Hudecováa, D.; Valigura, D. Acta Chim. Slovaca 2009, 2, 77-87.

8. Joullie, M. M.; Lassen, K. M. ARKIVOC 2010, No. viii, 189-250. doi:10.3998/ark.5550190.0011.816

9. Carpino, L. A. J. Am. Chem. Soc. 1993, 115, 4397-4398. doi:10.1021/ja00063a082

10. Amin, K.; Antonsson, T.; Bach, P.; Brown, D.; Bylund, R.; Giordanetto, F.; Hovdal, D.; Johansson, J. New pyridine analogues viii 518. WO Pat. Appl. WO2008085119A1, July 17, 2008.

11. Beadle, J. R.; Valiaeva, N.; Yang, G.; Yu, J.-H.; Broker, T. R.; Aldern, K. A.; Harden, E. A.; Keith, K. A.; Prichard, M. N.; Hartman, T.; Buckheit, R. W., Jr.; Chow, L. T.; Hostetler, K. Y. J. Med. Chem. 2016, 59, 10470-10478. doi:10.1021/acs.jmedchem.6b00659

12. Larson, G. L.; Fry, J. L. In Ionic and OrganometallicCatalyzed Organosilane Reductions; Wipf, P., Ed.; John Wiley \& Sons: Hoboken, NJ, USA, 2007.

13. Singh, A. S.; Kumar, D.; Mishra, N.; Tiwari, V. K. ChemistrySelect 2017, 2, 224-229. doi:10.1002/slct.201601830

14. Wang, Y.; Wu, Y.; Li, Y.; Tang, Y. Chem. Sci. 2017, 8, 3852-3857. doi:10.1039/c7sc00367f

15. Trujillo, J. I.; Huang, H.-C.; Neumann, W. L.; Mahoney, M. W.; Long, S.; Huang, W.; Garland, D. J.; Kusturin, C.; Abbas, Z.; South, M. S.; Reitz, D. B. Bioorg. Med. Chem. Lett. 2007, 17, 4568-4574. doi:10.1016/j.bmcl.2007.05.090

16. Preliminary LC-MS and ${ }^{1} \mathrm{H}$ NMR data supporting elements of the mechanism proposed in Scheme 4 are included in Supporting Information File 1.

17. Colombo, M.; Bossolo, S.; Aramini, A. J. Comb. Chem. 2009, 11, 335-337. doi:10.1021/cc900011z

18. Ho, T.-L. Chem. Rev. 1975, 75, 1-20. doi:10.1021/cr60293a001

19. Kim, T.-S.; Bauer, D.; Bellon, S.; Boezio, A.; Booker, S.; Choquette, D.; D'Amico, D. C.; D'Angelo, N.; Dominguez, C.; Fellows, I. M.; Germain, J.; Graceffa, R.; Harmange, J.-C.; Hirai, S.; La, D.; Lee, M.; Liu, L.; Norman, M. H.; Potashman, M.; Roveto, P.; Siegmund, A. C.; $\mathrm{Xi}, \mathrm{N}$.; Yang, K. Substituted amide derivatives as protein kinase inhibitors. WO Pat. Appl. WO2006116713A1, Nov 2, 2006.

20. Coleman, R. S.; Shah, J. A. Synthesis 1999, 1399-1400. doi:10.1055/s-1999-3664 


\section{License and Terms}

This is an Open Access article under the terms of the Creative Commons Attribution License (https://creativecommons.org/licenses/by/4.0). Please note that the reuse, redistribution and reproduction in particular requires that the author(s) and source are credited and that individual graphics may be subject to special legal provisions.

The license is subject to the Beilstein Journal of Organic Chemistry terms and conditions:

(https://www.beilstein-journals.org/bjoc/terms)

The definitive version of this article is the electronic one which can be found at:

https://doi.org/10.3762/bjoc.17.16 